B.S. Silbert FFaracs fFarCs, G.C. Dixon fFaracs, R. Kluger FFARACS, J. Berg FFARCS

\title{
Epidural opioids as anaesthesia for extra- corporeal shock wave lithotripsy in two patients with cardiac disease
}

Two patients with cardiac disease underwent Extracorporeal Shock Wave Lithotripsy (ESWL) in the Dornier HM3 machine. In order to minimize cardiovascular changes, epidural opioids (jentanyl $100 \mu \mathrm{g}$ in $10 \mathrm{ml}$ saline was used in one patient and meperidine $50 \mathrm{mg}$ in $10 \mathrm{~m}$ ( saline in the other patient) were used as an aliernative to either general andesthesia or epidural local anaesthesia. Borh patients displayed haemodynamic stability, remained pain-free and experienced no complications. Epidural opioids proved a switable form of anaesthesia for ESWL in these patients

Extracorporeal shock wave lithotripsy (ESWL) is an effective, noninvasive method for the treatment of renal calculi. High pressure shockwaves are propagated through water, to focus onto a uninary calculus causing it to shatter into fine particles which are then passed in the urine. With the Dornier HM3 machine the procedure is painful and requires anaesthesia. Many patients require some ancillary procedure in conjunction with ESWL, e.g., placement of a ureteric stent to aid the passage of the particles or pushing calculi from the ureter to the renal pelvis where treatment is more satisfactory.

Because both general anaesthesia and epidural anaesthesia with local anaesthetic agents may produce unwanted haemodynamic changes, we decided to use epidural opioids (fentanyl and meperidine) in two patients with

\section{Key words}

EXTRACORPOREAL SHOCK WAVE LITHOTRIPSY (ESWL): EPIDURAL OPIOIDS: fentanyl, meperidine; CARDIAC DISEASE: aortic valvular disease, left ventricular failure.

From the Department of Anaesthesia, St. Vincent's Hospital, Victoria Parade, Fitzroy, Victoria 3065, Australia.

Address correspondence to: Dr. Silbert. cardiac disease. Reports of this technique for ESWL are limited. ${ }^{1-4}$

\section{Case reports}

\section{Patient I}

A 56-year-old man with mixed aortic valve disease presented for an elective aortic valve replacement. However, on admission, he complained of loin pain. Further questioning revealed an 11-year history of renal calculi. His current loin pain had been present for three weeks and had been relieved by antispasmodics and analgcsics. Abdominal $x$-ray showed a calculus in the lower pole of the left kidney and this was confirmed by intravenous pyelogram.

He suffered from hypertension and angina which was relieved by sublingual glyceryl trinitrate and had a past history of a myocardial infarction four years previously. No episodes of syncope had been reported. He was becoming progressively dyspnoeic on moderate exertion. Medications included amiloride $5 \mathrm{mg}$ daily, atenolol 50 $\mathrm{mg}$ daily, prazosin $2 \mathrm{mg}$ twice daily, and isordil $10 \mathrm{mg}$ four times daily.

An ECG displayed left ventricular hypertrophy and strain and on chest $x$-ray the left ventricle contour suggested mild left ventricular enlargement, although the cardiac size was within normal limits. Angiography showed an aortic valve gradient of $64 \mathrm{mmHg}$, grade 3 aortic regurgitation and normal coronary arteries.

It was decided to delay aortic valvular replacement until the renal calculi had been treated with ESWL, following insertion of a ureteric stent. This would avoid the risk of endocarditis as a result of renal tract infection.

On arrival in the operating theatre an intravenous infusion was commenced and oxygen administerecd at 6 $\mathrm{L} \cdot \mathrm{min}^{-1}$ by face mask A 20 gauge cannula was inserted in a radial artery for continuous direct arterial blood 
pressure measurement. Initial blood pressure was $130 / 70$ $\mathrm{mmHg}$ and pulse rate 100 beats $\cdot \mathrm{min}^{-1}$. A lead II ECG and arterial blood pressure were continuously recorded on a paper chart. Three $\mathrm{mg}$ of intravenous midazolam was given for sedation. The patient was placed in the left lateral position and an 18 gauge epidural catheter introduced into the $\mathrm{L}_{2-3}$ interspace without difficulty. A test dose of $2 \mathrm{ml}$ of 1.5 per cent lidocaine with epinephrine was injected.

Fifteen $\mathrm{ml}$ of two per cent prilocaine plain was then injected via a 21 gauge needle into the caudal space to produce a saddle block for cystoscopy and insertion of the stent. Pin prick confirmed a limited area of sacral anaesthesia. Following stent insertion $50 \mathrm{mg}$ of meperidine in $10 \mathrm{ml}$ saline was injected into the epidural catheter prior to positioning the patient in the waterbath for ESWL.

The patient underwent 2,500 shocks at $18 \mathrm{Kv}$ with one electrode change and remained pain-free and comfortable during the treatment. 'There were no significant changes in either heart rate or blood pressure at any stage (systolic blood pressure remained between $130-155 \mathrm{mmHg}$; diastolic blood pressure $65-80 \mathrm{mmHg}$ and pulse ratc $80-100$ beats $\cdot \min ^{-1}$ ). Two hundred $\mathrm{ml}$ of crystalloid was administered during the 90-minute procedure. There were no complications postoperatively.

\section{Patient 2}

A 55-year-old man with a left lower pole renal calculus presented for ESWL. Five months prior to this admission he had developed rapid atrial fibrillation with lefi ventricular failure. Echocardiography had shown global left ventricular impairment and a dilated left ventricle. There was no evidence of ischaemia or valvular lesions and no cause found for the atrial fibrillation. The patient had been stabilised with digoxin and diuretic therapy but still suffered from dyspnoea and exhaustion on minimal exertion.

Preoperatively he was in atrial fibrillation with a controlled ventricular rate of 85 beats $\cdot \mathrm{min}^{-1}$ and blood pressure $120 / 70 \mathrm{mmHg}$. Both clinical examination and chest $x$-ray showed the presence of cardiomegaly with clear lung fields. No premedication was given. An intravenous infusion was commenced and a 20 gauge cannula was inserted in a radial artery for direct arterial blood pressure measurement. A lead II ECG and arterial blood pressure were continuously recorded on a paper chart. Midazolam $2 \mathrm{mg}$ was administered intravenously and oxygen was given by face mask at $6 \mathrm{~L} \cdot \mathrm{min}^{-1}$.

An epidural catheter was inserted in the $L_{1-2}$ interspace and following a test dose of $3 \mathrm{ml} \$ .5$ per cent lidocaine with epinephrine, $100 \mathrm{ug}$ fentanyl in $10 \mathrm{ml}$ of saline was administered epidurally. The patient was positioned in the ESWL bath and underwent 1600 shocks at $22 \mathrm{kV}$ over 20 minutes. One hundred and fifty $\mathrm{ml}$ of crystalloid was administered during the procedure.

His initial blood pressure was $115 / 70 \mathrm{mmHg}$ with an average heart rate of 85 beats min $^{-1}$. At no stage was there any significant change in either heart rate or blood pressure (systolic blood pressure remained between 105 $120 \mathrm{mmHg}$; diastolic blood pressure $67-75 \mathrm{mmHg}$ and heart rate 80-90 bpm). The patient remained comfortable and pain-free throughout the treatment. His post-treatment course was unremarkable.

\section{Discussion}

Patients scheduled for cardiac valve replacement who are suffering from renal calculi amenable to ESWL should undergo treatment before cardiac surgery. This avoids the risk of bacteraemia resulting from renal tract infection and the subsequent risk of endocarditis. Further, if the prosthetic valve requires the patient to be anticoagulated, ESWL cannot be undertaken safely because of the risk of perinephric bleeding secondary to the shock waves.

ESWL, using the Domier HM3 machine, is painful because of the pressures generated $(900-1200$ bar at the focal point). For this reason some form of anaesthesia is required. General anaesthesia ${ }^{5}$ or epidural anaesthesia ${ }^{6}$ ure most commonly used although intercostal nerve blocks with local infiltration have been employed." General anaesthesia and epidural anaesthesia are often associated with unwanted cardiovascular changes particularly in patients with cardiac disease. Intercostal blocks with local infiltration do not prevent the visceral compo nent of pain, the autonomic responses of which may cause adverse cardiovascular effects. Systemic levels of local anaesthetic agents may further depress a compromised myocardium. ${ }^{8}$ The semi-reclining position for ESWL and immersion in the waterbath can pose further cardiovascular stresses. ${ }^{9.10}$ Weber et al. reported a fatality during ESWL in a patient suffering from ischaemic heart disease and aortic stenosis. "

It is important that patients with valvular heart disease andior curdiomyopathy are managed in a manner that maintains cardiovascular stability. For this reason we chose to use an epidural opioid, combined with intravenous midazolam sedation.

The main advantages of the technique are the absence of autonomic side effects which could cause cardiovascular changes, and the avoidance of myocardial depression by general anaesthetic agents or systemic local anaesthetic levels, whilst maintaining the inherent safety of an awake patient during ESWL and ancillary procedures. 
Continuous intra-arterial and ECG monitoring in these cases confirmed cardiovascular stability throughout the procedures. The use of caudal anaesthesia for placement of the stent, in the patient with aortic stenosis, was chosen for its minimal cardiovascular effects.

No undesirable side effects of epidural opioids, such as nausea and vomiting, pruritis, respiratory or central nervous system depression, were observed in either case.

At this point in time, machines incorporating improved technology are becoming available. Domier have modified the shock wave generator of the HM3 to allow reduced focus pressure at the same energy level $(600$ bar compared to 900 bar at $18 \mathrm{kV}$ ). This reduces pain perception allowing most patients to be treated satisfactorily with oral anxiolytics and analgesics. ${ }^{12}$ Anaesthesia is still required for some patients and for ancillary procedures, which are required in approximately 25 per cent of patients. ${ }^{13}$ A new machine, the Dornier HM4, also uses a water cushion, applied to the patient's back and loins, to eliminate the waterbath.

In addition three other bath-free machines have been developed. Two utilise piezoelectric energy sources which cause minimal discomfort. The EDAP LT.01 requires neurolept analgesia or sedation and the Wolf Piezolith enables most patients to be treated without medication. ${ }^{14,15}$ A third machine, the Siemens Lithostar, uses an electromagnetic shock wave generator and usually requires anaesthesia. ${ }^{16}$ None of these machines has yet proven to be quite as effective as the Dornier machines in terms of stone disintegration. ${ }^{17}$

In sumunary, patients with cardiac disease presenting for ESWL in the Domier HM3 represent a challenge to the anaes thetist. In these two cases epidural opioids proved a suitable method of anaesthesia with minimal cardiovascular disturbance. In the future the newer generation of lithotripter machines may obviate the need for waterbaths and reduce the requirements for anaesthesia.

\section{References}

I Gissen D, Naroll M, Katz RL. Epidural fentanyl for extra-corporeal shock wave lithotripsy (ESWL). Regional Anesthesia 1988; 13:40-3.

2 Wells DG, Davies G. Profound central nervous system depression from epidural fentanyl for extracorporeal shock wave lithotripsy. Anesthesiology 1987; 67: 991-2.

3 Pundit SK, Powell RB, Crider b, McLaren ID, Rutter $T$. Epidural fentanyl: a simple and novel approach to anesthetic management for extracorporeal shock wave lithotripsy (ESWL) (Abstract). Anesthesiology 1987; 67; A225.

4 Pandit SK, Powell RB, Crider B, MCLaren ID, Runter
$T$. Epidural fentanyl is not effective for analgesia for extracorporeal lithotripsy (ESWL). Anesthesiology 1988; 68: 176-7.

5 Abbout MA, Samuel JR, Webb DR. Anathesia for extracorporeal shock wave lithotripsy. Anacsthesia $1985 ; 40$ : 1065-72.

6 Duvall JO. Griffith DP. Epidural anesthesia for extracorporea! shock wave lithotripsy. Anesth Analg 1985; 64: 544-6.

7 Malhotra V, Long CW, Meister MJ. Intercostal blocks with local infiltration ancsthesia for extracorporeal shock wave lithotripsy. Anesth Analg 1987; 66: 85-8.

8 Ritchie $J M$, Greene NM. Local Anaesthetics. In: Goodman AG, Goodman LS, Gilman A. (Eds). The Pharmacological Basis of Therapeutics, 7 th ed. Macmillan Publishing Co., Inc. New Yonk, 1985, 307.

9 Weber W, Chaussy C, Madler C, Peter K, Schuller $J$. Cardiocirculatory changes during anesthesia for extracorporeal shock wave lithotripsy (ESWL). J Urol 1984; 4: 246A

10 Behnia R, Shanks CA, Ovassapian A, Wilson LA. Hemodynamic responses associated with lithotripsy. Anesth Analg 1987; 66: 354-6.

I) Weber W, Madler CH. Schmucker P, Peter K, Chaussy $\mathrm{CH}$. Aspects of shock wave treatment in patients with cardiac risk. Second World Congress on Percutaneous Renal Surgery June, 1984.

12 Fischer $N$, Rubben $H$, Hofsaß S, Forßmann B, Schackenhoff $B$, Giani $G$. Painless ESWL with the Dornier Lithotripter HM3. Urologe (A) 1987; 26:29-32.

13 Riehle RA. Fair WR, Vaughan ED Jr. Extracorporeal shock-wave lithotripsy for upper urinary tract calculi. JAMA 1986; 255: 2043-8.

14 Editor. The L.T.OI lithotripter: EDAP. In: Lithotripsy II. Coptcoat MJ, Miller RA, Wickham JEA. B.D.1. Publishing, London, 1987; 57-62.

15 Ziegler $M$, Kopper B, Riedlinger $R$. et al. Dic Zertrummenung von Nierensteinen mit einem piezoelektrischen Geratesstem. Erste klinische Erfahungen. Urologe (A) 1986: 25: 193 .

16 Clinical experience with the Siemens Lithostart. In: Lithutripsy II. Coptcoat MJ, Miller RA, Wickham JEA (Eds). Ch. 4, page 57. BDI Publishing, London 1987.

17 Flechs GJ, Chaussy CG. Current state and future developments of noninvasive treatment of human urinary and biliary stones with extracorporeal shock wave lithotripsy: an updale. Hospimedica September/Octuber 1987; $67-75$. 


\section{Résumé}

Deux patients atteints de maladie cardiaque ont subi une lithotripsie extracorporelle. Afin de diminuer les effets cardiovasculaires, une epidurale awx opiacés (fentanyl $100 \mu \mathrm{g}$ dans 10 $m l$ de physiologique a été utilisé chez un patient et de la méperidine $50 \mathrm{mg}$ dans $10 \mathrm{ml}$ de physiologique pour l'autre patient) ont été utilisés comme une alternative à l'anesthésie générale ou l'anesthésie épidurale. Les deux patients ont dérnontré une stabilité hémodynamique, sont demeurés libres de toute douleur et n'ont démontré aucune complication. L'utilisation des opiacés en épidurale est une façon convenabie d' dresthésier ces patients se présentant pour une lithorripsie. 